\title{
Protein phosphatase 1 nuclear targeting subunit is a hypoxia inducible gene: its role in post-translational modification of p53 and MDM2
}

\author{
S-J Lee ${ }^{1,2}$, C-J Lim² ${ }^{2}$ J-K Min' ${ }^{1}$, J-K Lee ${ }^{1,2}$, Y-M Kim³ ${ }^{3}$ J-Y Lee ${ }^{4}$ M-H Won ${ }^{5}$ and Y-G Kwon ${ }^{\star, 1}$
}

p53, the most commonly mutated tumor suppressor gene in human cancers, is a master regulator of apoptosis in many types of cells. Recently, protein phosphatase-1 (PP1) has emerged as a key phosphatase of p53, which modulates the interaction of p53 with its regulatory protein mouse double minute 2 (MDM2) and transcriptional activity. In the present study, we demonstrate the potential role of PP1 nuclear targeting subunit (PNUTS) in regulating the phosphorylation and apoptotic activities of p53. Hypoxia significantly increased mRNA and protein expression of PNUTS in various cell lines concomitantly with increases in p53. Promoter analysis confirmed the presence of hypoxia response elements in the promoter region of the PNUTS gene, which respond to hypoxia and forced expression of hypoxia-inducible factor $1 \alpha$. Overexpression of PNUTS markedly increased cell death in response to hypoxia, with increased expression of Bax, an apoptosis-related gene induced by p53. Consistently, PNUTS increased the nuclear localization, phosphorylation, and transcriptional activity of p53 as well as the ubiquitin-dependent proteosomal degradation of MDM2. However, the W401A mutant form of PNUTS, which is incapable of binding to PP1, failed to induce these events. Taken together, our findings suggest that PNUTS may play an important role in controlling cell death in response to cellular stresses such as hypoxia through the post-translational modification of p53 and MDM2.

Cell Death and Differentiation (2007) 14, 1106-1116. doi:10.1038/sj.cdd.4402111; published online 23 February 2007

Protein phosphatase-1 (PP1) is a multifunctional serine/ threonine phosphatase, which is ubiquitously expressed in eukaryotes and influences several aspects of cellular physiology. ${ }^{1-3}$ The catalytic subunit of PP1, which exists as four different isoforms (PP1 $\alpha,-\gamma 1,-\gamma 2$, and $-\delta$ ), is found in multiple subcellular compartments and its activities, localization, and substrate specificity are regulated by an alliance of numerous regulatory proteins. ${ }^{4}$

Protein phosphatase-1 nuclear targeting subunit (PNUTS), also called PP1R10 and p99, was originally isolated as a nuclear protein that forms a stable complex with PP1 $\alpha$ and PP1 $\gamma$ in mammalian cell lysates. ${ }^{5}$ PNUTS binds to PP1 through a consensus PP1-binding 'RVXF motif' (398TVTW401) and to homopolymeric RNA with high selectivity for poly $(A)$ and poly $(G)$ via the RGG motifs and His- and Gly-rich region in its C-terminus. ${ }^{6}$ Recombinant PNUTS potently decreases the catalytic activity of PP1 towards exogenous substrate in vitro, and forced expression of PNUTS in mammalian cells affects cell viability. ${ }^{6}$ Recently, it was also reported that PNUTS is targeted to restructure nuclei in telophase following the assembly of nuclear membranes and augments in vitro chromosome decondensation in a PP1-dependent manner. ${ }^{7}$ However, the exact function of PNUTS in vivo, including its role in depho- sphorylating physiological substrates of PP1, remains to be elucidated.

Hypoxia, a reduced availability of oxygen, has significant roles in both normal tissue development and progression of human diseases such as cancer and tissue ischemia. ${ }^{8}$ Particularly, in solid tumors, hypoxia is a common phenomenon because cells in rapidly growing tumors are intermittently, or sometimes constantly, exposed to hypoxic conditions resulting in impaired vascular function. ${ }^{8}$ The severity of hypoxia determines whether cells become apoptotic or adapt to hypoxia and survive. ${ }^{9}$ Tumor cells resistant to hypoxia are considered to be a more aggressive phenotype and may have decreased responsiveness to treatment. Apoptosis of tumor cells in hypoxic environments is regulated by a delicate balance of apoptosis regulatory proteins. ${ }^{9}$ It has been demonstrated that in p53-positive tumors, exposure to severe hypoxia leads to the accumulation of $\mathrm{p} 53$, which can, in turn, lead to rapid apoptosis. ${ }^{10}$ Further, understanding the regulatory mechanism of apoptosis during hypoxia and identifying the means to enhance tumor cell apoptosis might lead to more specific treatments for solid tumors.

p53, the most commonly mutated tumor suppressor gene in human cancers, is a master regulator of apoptosis in many types of cells. Cellular responses of p53 are tightly regulated

\footnotetext{
${ }^{1}$ Department of Biochemistry, College of Sciences, Yonsei University, Shinchon-dong, Seodaemoon-gu, Seoul, Korea; ${ }^{2}$ Department of Biochemistry, College of Natural Sciences, Kangwon National University, Chunchon, Kangwon-Do, Korea; ${ }^{3}$ Vascular System Research Center, Kangwon National University, Chunchon, Kangwon-Do, Korea; ${ }^{4}$ Department of Biochemistry, Hallym University, Chuncheon, Gangwon-do, Korea and ${ }^{5}$ Department of Anatomy, College of Medicine, Hallym University, Okchon-dong, Chuncheon, Gangwon-do, Korea

${ }^{*}$ Corresponding author: Y-G Kwon, Department of Biochemistry, College of Sciences, Yonsei University, Seoul, 120-749, Korea.

Tel: + 8222123 5697; Fax: + 822362 9897; E-mail: ygkwon@yonsei.ac.kr

Keywords: PNUTS; p53; MDM2; hypoxia; cell death; post-translational modification

Abbreviations: PNUTS, protein phosphatase-1 nuclear targeting subunit; PP1, protein phosphatase-1; DFO, desferrioxamine; HREs, hypoxia response elements; HIF- $1 \alpha$, hypoxia-inducible factor $1 \alpha$; MDM2, murine double minute 2; ATM, ataxia telangiectasia mutated

Received 26.6.06; revised 03.1.07; accepted 04.1.07; Edited by K Vousden; published online 23.2.07
} 
by post-translational modifications including phosphorylation, acetylation, ubiquitylation, and sumoylation that impinge on both protein stability and sequence-specific DNA binding ability. ${ }^{11}$ Murine double minute 2 (MDM2), the predominant negative regulator of p53, acts as a specific E3 ligase for p53 and thus promotes p53 ubiquitination and degradation. ${ }^{12-16}$ p53 is phosphorylated at multiple sites at the $\mathrm{N}$ - and $\mathrm{C}$-termini in vitro and in vivo by a number of kinases including Chk2 kinase, which is activated by ataxia telangiectasia mutated (ATM) family kinases after DNA damage or other types of cellular stress. ${ }^{14,17}$ The phosphorylated p53 then causes cell growth arrest and/or apoptosis through p53 target gene transcription. ${ }^{17}$ Among many phosphorylation sites of p53, phosphorylation at serine 15 has been best characterized and shown to lead to p53 stabilization and an increase in protein levels and transcriptional activity. ${ }^{17,18}$ However, the precise regulatory mechanisms of stress-induced site-specific dephosphorylation of p53 are much less known. Recently, it has been demonstrated that PP1 can dephosphorylate p53 at Ser15 and Ser37 in human lens epithelial cells, and dephosphorylation of these sites changes the transcriptional activity and apoptotic capacity of p53. ${ }^{19}$ Moreover, PP1 dephosphorylated phospho-p53 (Ser15) in response to ultraviolet C (UVC), and GADD34, a regulator of PP1, interfered with this dephosphorylation, thus augmenting the amount of phosphop53 after UVC treatment. ${ }^{20}$ These results suggest a significant involvement of PP1 and its regulatory proteins in controlling the phosphorylation state and function of $\mathrm{p} 53$.

The current study was undertaken to examine the plausible relationship between the nuclear PP1 binding protein PNUTS and p53. We demonstrated that PNUTS was upregulated in various cells by hypoxia, which also induces expression and phosphorylation of p53. Furthermore, overexpression of PNUTS significantly influenced MDM2 degradation as well as the localization, phosphorylation (Ser15), and transcriptional activity of p53.

\section{Results}

PNUTS is upregulated in EC219 and HEK 293 cells by hypoxia and desferrioxamine. Because it has been recognized that a hypoxic microenvironment emerges under a number of physiopathological conditions, we first examined the expression of PNUTS in various cells in response to hypoxia. As shown in Figure 1a, PNUTS protein expression was induced $2 \mathrm{~h}$ after exposure to hypoxia. Its expression pattern resembled that of $p 53$, which is the bestcharacterized hypoxia responsive gene. Consistently, it was also induced by desferrioxamine (DFO), a hypoxia-mimetic agent (Figure 1d). Semiquantitative RT-PCR analysis also demonstrated corresponding significant induction of PNUTS mRNA in EC219 and HEK 293 cells. VEGF was used as a marker of hypoxia (Figure 1e and f).

Identification of a functional HRE in the human PNUTS gene promoter. To further confirm hypoxia-induced PNUTS expression, we cloned the potential promoter region of the PNUTS gene from a human brain genomic DNA library. The sequence of the PNUTS promoter was predicted to be
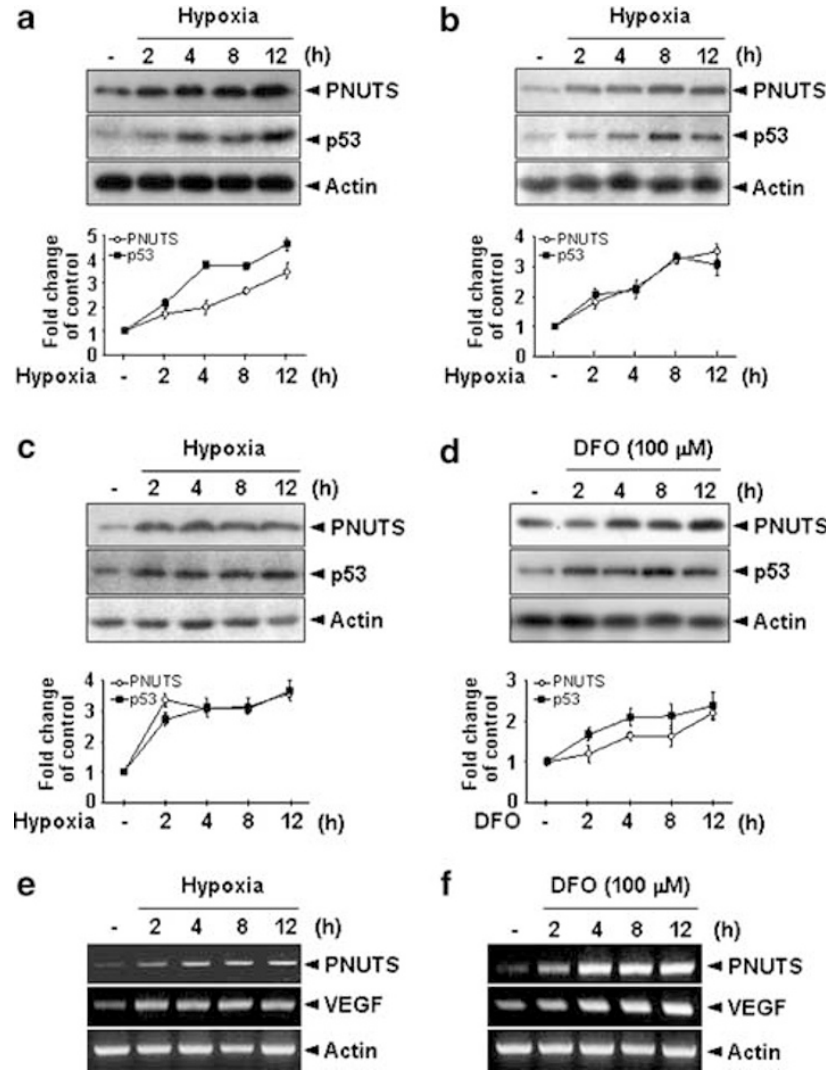

Figure 1 Hypoxia induces expression of PNUTS protein and mRNA. (a-c) All three cell lines (a, EC219; b, HEK 293; c, HUVEC) were cultured in a hypoxic chamber (hypoxia, $0 \% \mathrm{O}_{2}$ ) or a regular incubator (normoxia, $21 \% \mathrm{O}_{2}$ ) for $2,4,8$, and $12 \mathrm{~h}$ (d) EC219 cells were cultured in the presence or absence of $100 \mu \mathrm{M} \mathrm{DFO}$ for 2 , 4,8 , and $12 \mathrm{~h}$. Cells were then lysed and separated by SDS-PAGE gel, and Western blot was performed with the respective antibodies. PNUTS and p53 densitometry analysis is shown on the bottom. (e, f) Total RNAs isolated from EC219 cells treated with hypoxia (e) or DFO (f) for 2, 4, 8, and $12 \mathrm{~h}$ were reverse transcribed and amplified with 25 PCR cycles. Actin was used as a control. Equal volumes were loaded on a $1 \%$ agarose gel containing ethidium bromide

$5^{\prime}$-flanking region up to $1216 \mathrm{bp}$ of first exon of PNUTS gene (Figure 2a and b), and basal promoter activity of this region was ascertained by luciferase assay (Figure $2 \mathrm{c}$ ). A substantial increase in reporter activity was also observed after exposing cells transfected with the PNUTS promoter luciferase reporter construct to $0 \%$ oxygen (Figure $3 a$ ). Comparable results were observed with DFO (Figure $3 b$ ).

On the basis of these data, we examined the potential role of HIF-1 $\alpha$ in the transcriptional regulation of hypoxia-induced PNUTS upregulation. The sequence of the PNUTS promoter was confirmed and analyzed for putative HRE sites. An HRE matrix containing the core sequence $\left(5^{\prime}-\mathrm{RCGTG}-3^{\prime}\right)$ in the PNUTS promoter was recognized at -795 to $-791,-775$ to -771 , and -489 to -485 (Figure $2 a$ ). To test the efficacy of this HRE matrix, $5^{\prime}$-deletion mutants of the PNUTS promoter $(-978$ to $+22,-728$ to $+22,-478$ to +22$)$ were cloned into the pGL3-Basic luciferase reporter plasmid (Figure 3c), and the resultant plasmids were introduced into HEK 293 cells. A significant increase in the reporter gene expression was observed in cells transfected with the -1216 to +22 and -978 to +22 constructs after being exposed to DFO 
-1216 gagaaactgt cctcaggtcg taagaatata tcctgacctt attgagaaat agcaaggttg

-1156 gtagaaattg ggatccctaa tttccccaag gacattccag agcaacacag atttagtcac

-1096 cact tgcata gttaacagct ggttgt ggcg ctcgcttggg gagtacatat gttatgctaa

-1036 aattgcaacg at acagagat tagcatggcc ccttaattag ttaaataatt tttaaaaagc

-976 tggttatgca tgactgaggg tggacagggg tcaattccat cacttaagtt attttactga

-916 aatggcatt t tggaaaaagg at gataccta accctggcgt ttagtcctcg gctcgggatt

-856 agaaaatgcg cggggtgtgg gggggggtt gcaggaagta ctgcctagac agctaagaca

-796 cacgtgggaa ggtctccact cgtggattcc tgacagtgga gcgacaacct cgagaaggta

-736 taaccaact $t$ gaggttgtgc aaaatgtctt tcgaagagtt acctgaactc tgtgagaacc

-676 tcggaagaga gatagcatag gaagccgcct cagcacggtg tttaatacag acgccgccat

-616 ct tgacgtac gcccaggaca ggaattgacg gaaaggcaac tgcgcatgct tcaggaaact

-556 gagtagggca gggccaagga caagcccgca gt gcggaagg cggccccacg tttgcgtcag

-496 gacggaagcg tgaaagggaa ggcatggggg agaagctaat ttcaactgcg tcacaatcga

-436 at tagacccc aaaattgcgg tttttttgg ccagtcacta cgactcttag atcgcat tgt

-376 taaagtttgc cttttaagca attttgaagg cgatttttag cggtatcctc tcagtgcgca

-316 tgcgctctta ggtttctacc aatcctgggt gagaaatgtt ctccagggcg gaagtggcgg

-256 aagcagagga aagggaggt g ctaggctcct ggtcacgcgc acgcgacagg gaggcaggaa

-196 ggaggcggaa gagagtgcca gggaaagggg cggagcaaag gtgaagtgag agtagccaat

-136 cagtt ggcga gtt gtcatt gggt tgacca at gagttcac gcctcgcgta taat gtctcg

-76 cgacaagggc gtttcactag cacgtttggg cgcgttgggC ggcgtccggg tataaaagac

-16 tccacccgag cgggcggccg ccattctggg gttcgttt

TATA bOX

Exon1
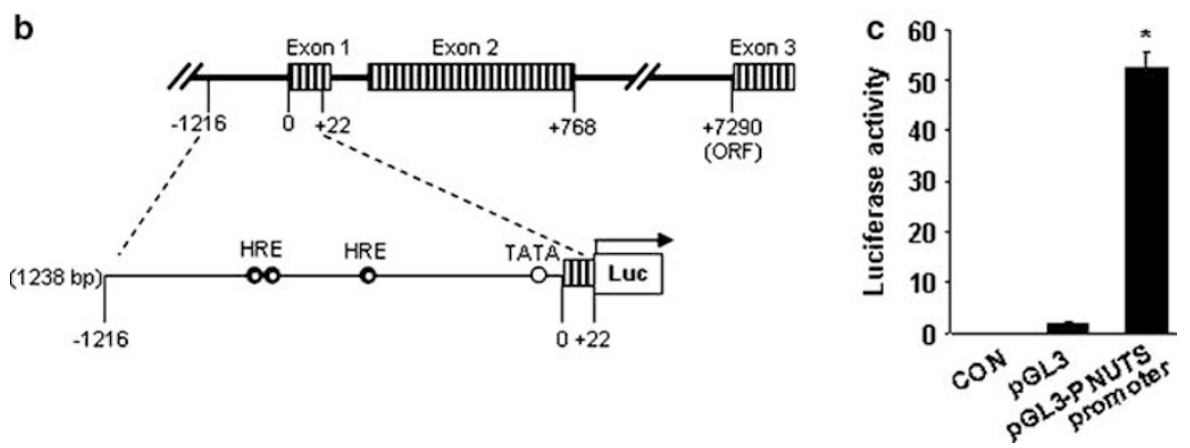

Figure 2 Cloning and characterization of the human PNUTS gene promoter. (a) The promoter sequence of PNUTS with three HREs highlighted in gray. The first exon at position +1 is boldfaced. (b) Schematic drawing of the human PNUTS promoter. (c) Measurement of basal PNUTS promoter activity in HEK 293 cells. Similar results were obtained in three additional experiments with data averaged in graph as mean \pm S.E.M. ( ${ }^{*} P<0.001$ versus $\left.p G L 3\right)$

(Figure 3d) or in those transfected with HIF-1 $\alpha$ (Figure 3e). To further examine the functional roles of two putative HREs (HRE-1 and HRE-2) in the PNUTS promoter, deletion mutants of these HRE sites were prepared as described in Figure $3 \mathrm{~g}$. Promoter activity increased by either DFO or HIF-1 $\alpha$ transfection was decreased near to the control level by deletion of the first HRE site but it was not significantly affected by removing the second HRE site (Figure 3h), indicating the specific sequence of functional HRE in the PNUTS promoter. Additionally, increases in the protein and mRNA levels of PNUTS were observed after forced expression of HIF- $1 \alpha$ (Figure 3f). Taken together, these data suggest a functional role for HIF- $1 \alpha$ in the transcriptional activation of PNUTS under hypoxic conditions.

Overexpression of PNUTS increases hypoxia-induced cell death. To identify the role of PNUTS in the cellular response to hypoxia, cells were either mock-infected or infected with retroviruses encoding rat PNUTS. Overexpression of PNUTS significantly increased cell death compared to mock-infected cells after 12 or $24 \mathrm{~h}$ of hypoxia as measured by direct cell number counting (Figure 4a). Consistently, the levels of Bax, active caspase-3, and cleaved PARP, apoptotic markers, were markedly increased in cells overexpressing PNUTS in response to hypoxia compared to mock-infected cells (Figure 4b). Similar results were observed when cells were treated with DFO (Figure $4 \mathrm{c}$ and $\mathrm{d}$ ). However, overexpression of the PNUTS mutant, W401A, which has a tryptophan to alanine mutation at the 401 position and is incapable of binding to PP1, failed to enhance cell death in response to DFO (Figure 4c). Consistently, it did not affect Bax expression and PARP cleavage (Figure 4d). We further examined whether the effect of PNUTS on apoptotic cell death is p53-dependent. Overexpression of PNUTS significantly enhanced DFOinduced apoptosis in wild-type MEF but had no significant effect in p53 null cells (Figure 4e), indicating that the p53 pathway is involved in the enhancement of apoptotic cell death by PNUTS. Taken together, these results suggest that PNUTS increases the sensitivity of cells to hypoxia-induced 

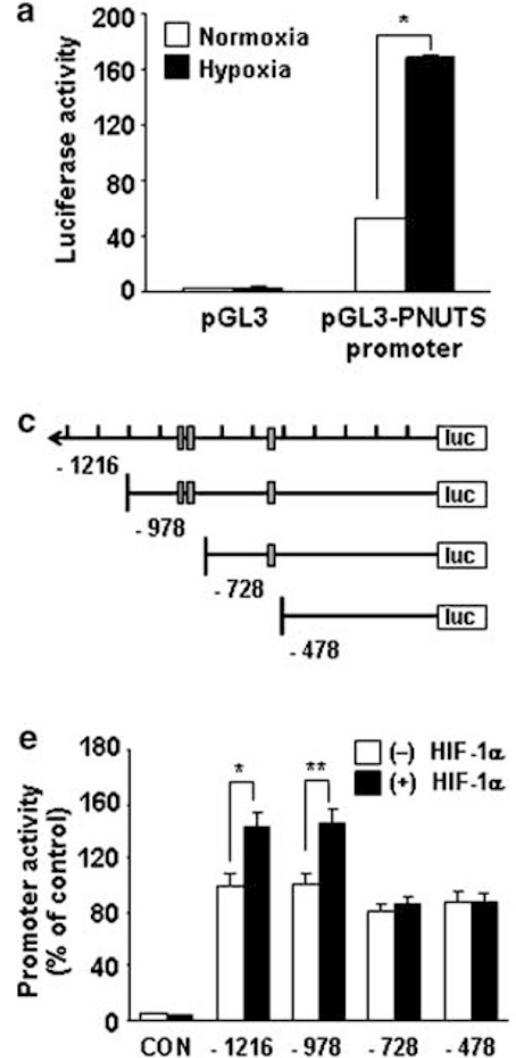

g

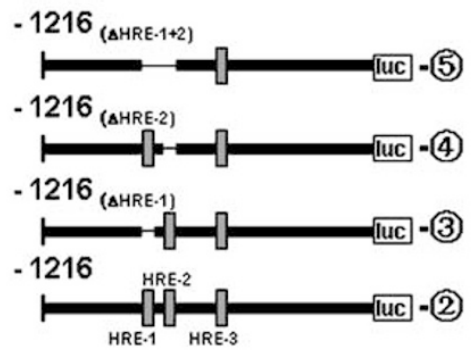

Iuc-1) b
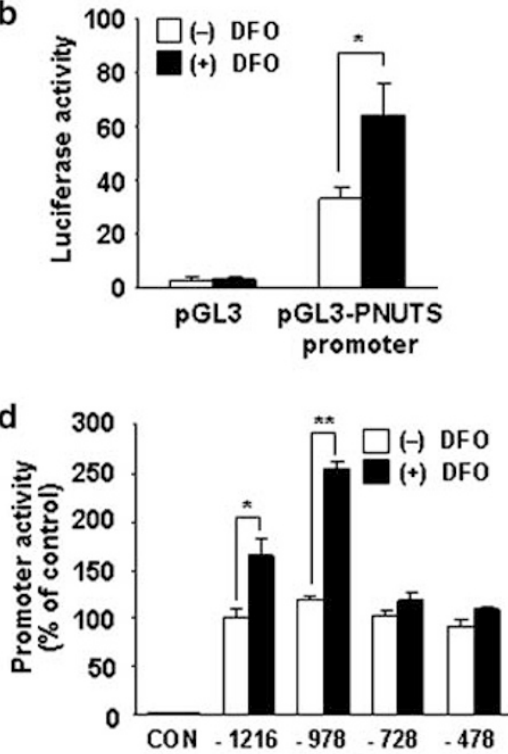

f
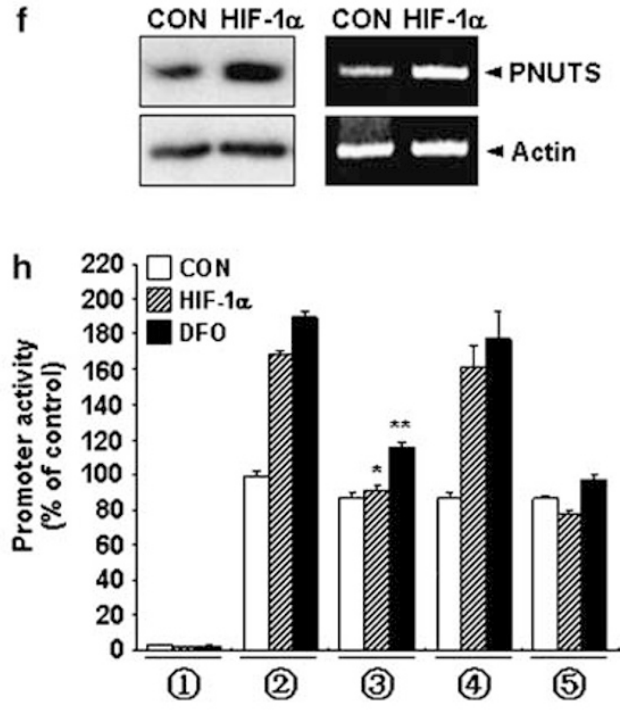

Figure 3 Promoter activity of PNUTS is increased by hypoxia and regulated by HIF-1 $\alpha$. (a) HEK 293 cells were transfected with the pGL3-Basic plasmid or the pGL3-Basic plasmid containing the human PNUTS promoter and subjected to normoxia or hypoxia treatment as detailed in Materials and Methods. Data show means and S.E. of three independent experiments performed in duplicate $\left({ }^{\star} P<0.001\right)$. (b) Transfected HEK 293 cells were treated with $100 \mu \mathrm{M}$ DFO for $8 \mathrm{~h}$ and luciferase activity was measured $\left({ }^{\star} P<0.001, n=3\right)$. (c) Schematic drawing of human PNUTS promoter deletion mutants $(-1216$ to $+22,-978$ to $+22,-728$ to $+22,-478$ to +22$)$. (d) HEK 293 cells were transfected with the full-length PNUTS promoter or deletion mutants, and treated with or without DFO $(100 \mu \mathrm{M})$ for $8 \mathrm{~h}\left({ }^{\star} P<0.001,{ }^{\star *} P<0.0001, n=3\right)$. (e) Cells were cotransfected with the full-length PNUTS promoter or deletion mutants and HIF-1 $\alpha$, and luciferase activity was measured $\left({ }^{\star} P<0.001,{ }^{* \star} P<0.0001, n=5\right)$. (f) HEK 293 cells were transfected with or without HIF- $1 \alpha$ for $24 \mathrm{~h}$ and levels of endogenous PNUTS protein (left panel) and PNUTS mRNA transcripts (right panel) were determined by Western blot and RT-PCR, respectively. (g) Schematic drawing of HRE deletion mutants on human PNUTS full promoter; - Mock, $\alpha$ human PNUTS full promoter, $\beta \Delta$ HRE- 1 ( $\Delta-795$ to -791$), \chi$ HRE-2 ( $\Delta-775$ to -771$), \delta \Delta$ HRE-1, 2. (h) HEK 293 cells were transfected with PNUTS full promoter or HRE deletion mutants after being exposed to $100 \mu \mathrm{M}$ DFO for $8 \mathrm{~h}$ or transfected with HIF- $1 \alpha$ and luciferase activity was measured $\left({ }^{*} P<0.001, n=3\right)$. CON means without HIF- $1 \alpha$ and DFO

death, presumably through upregulation of p53-dependent pro-apoptotic genes.

Overexpression of PNUTS increases nuclear localization, serine 15 phosphorylation, and transcriptional activity of p53. In view of the fact that p53 plays an important role in regulating cell death in response to hypoxia, we examined the effect of PNUTS on post-translational modification and transcriptional activity of p53. Forced expression of wild-type PNUTS (wt PNUTS) strongly increased phosphorylation of p53 at serine 15, one of the regulatory phosphorylation sites for transcriptional activity of p53 (Figure 5b), with little or very slight increase in total p53 level. This effect was further enhanced by treatment with DFO for $8 \mathrm{~h}$ (Figure $5 \mathrm{c}$ ). However, overexpression of the PNUTS mutant, W401A, had no significant effect on p53 phosphorylation (Figure $5 \mathrm{~b}$ ). Moreover, transfection of cells with wild-type PNUTS resulted in nuclear re-localization of 
a

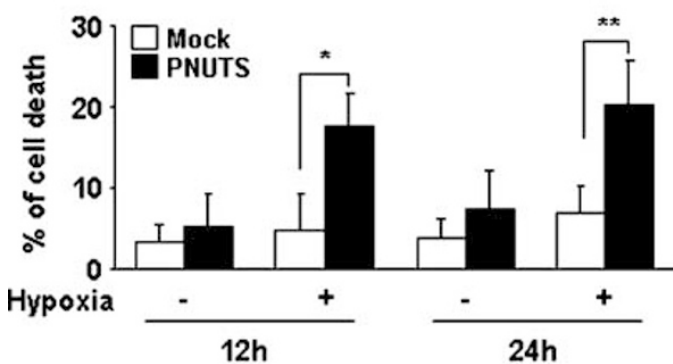

b - + + Hypoxia (24 h)

$++\cdot+$ PNUTS

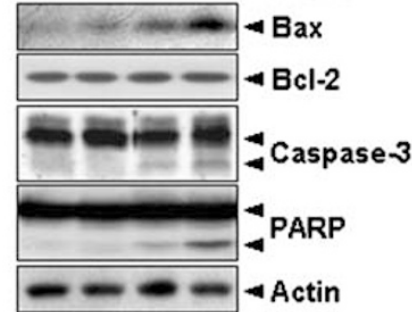

C

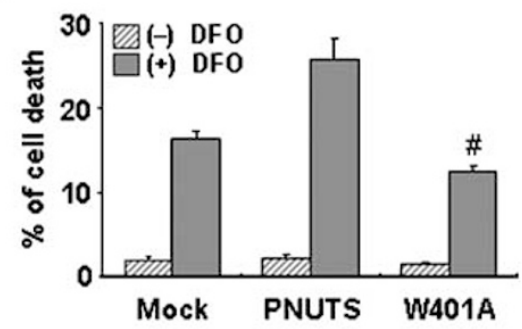

d Mock PNUTSW401A
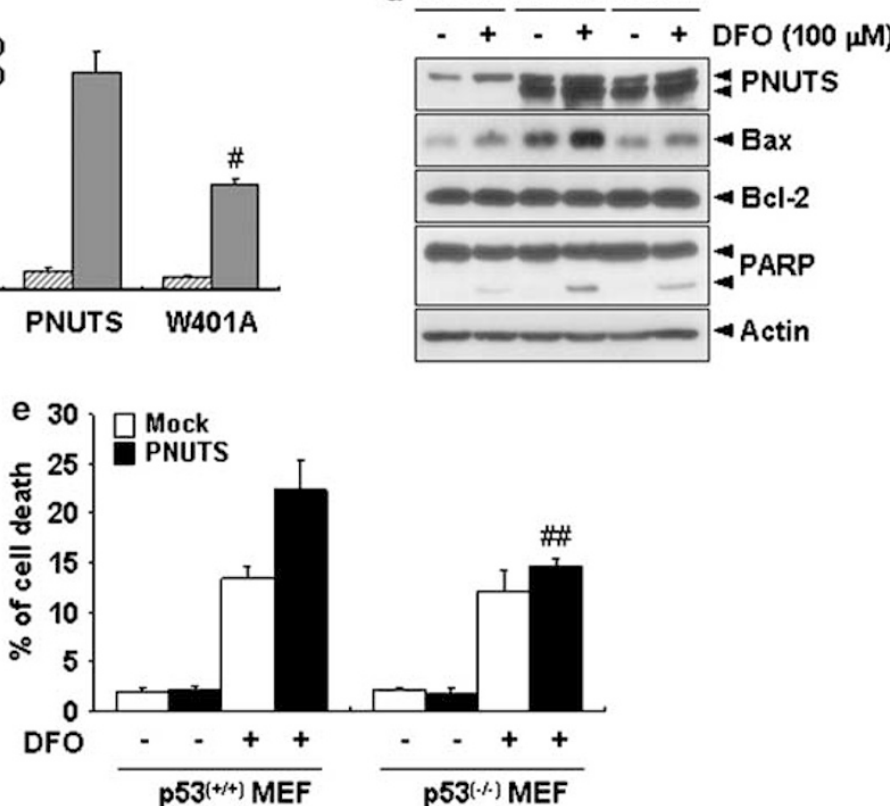

Figure 4 Overexpression of PNUTS increases hypoxia-induced cell death. (a) EC219 cells were either mock-infected or infected with retroviruses encoding rat PNUTS and incubated for 12 or $24 \mathrm{~h}$ under hypoxia or normoxia conditions. Cells were then analyzed by Trypan blue staining. (b) Detection of Bax, Bcl-2, caspase-3, and PARP by Western blot analysis. (c) HEK 293 cells transfected with pcDNA 3.1 plasmid containing PNUTS or W401A mutant for $24 \mathrm{~h}$ and treated with $100 \mu \mathrm{M} \mathrm{DFO}$ for $36 \mathrm{~h}$. (d) Detection of apoptotic markers by Western blot analysis. (e) $p 53^{(+/+)}$MEF (mouse embryonic fibroblasts) and $p 53^{(-l-)}$ MEF cells were either mock-infected or infected with retroviruses encoding rat PNUTS and treated with $100 \mu \mathrm{M}$ DFO for $24 \mathrm{~h}$. Cells were then analyzed by annexin V staining (c, e). Values shown are the mean \pm S.E.M. for six experiments $\left({ }^{\star} P<0.001,{ }^{* *} P<0.0001,{ }^{\#} P<0.01\right.$ versus PNUTS + DFO, ${ }^{\# \#} P<0.005$ versus PNUTS overexpressed $p 53^{(+l+)}$ MEF + DFO)

cytosolic p53 (Figure 5d) and increased serine 15 phosphorylation of p53 in the nucleus (Figure 5e).

We next assessed the effect of PNUTS on p53-dependent transcriptional activity using the p53-responsive promoter of p21. PNUTS alone had a modest stimulatory effect on p21 promoter activity (Figure 6a). This effect was significantly enhanced when cells were cotransfected with p53 but was inhibited by dominant-negative p53 (DNp53) (Figure 6a). Conversely, downregulation of endogenous PNUTS by siRNA administration repressed the transcriptional activity of p53 (Figure 6b).

Downregulation of MDM2 protein by PNUTS through the MDM2 ubiquitination pathway. The effects of PNUTS on MDM2 protein expression and stability were investigated. Forced expression of wild-type PNUTS but not the W401A mutant resulted in decreased MDM2 protein expression without affecting mRNA expression (Figure 7a). This change was restored by treatment with the proteosome inhibitors MG132 or lactacystin (Figure 7b). Consistently, overexpression of wild-type PNUTS but not the W401A mutant significantly increased the amount of polyubiquitinated MDM2 (Figure 7c). Moreover, downregulation of MDM2 in the nuclei of cells transfected with GFP-PNUTS was evident compared to their GFP-transfected counterparts (Figure 7d).

PNUTS overexpression suppressed the targeting of PP1 to MDM2-associated complexes and resulted in increased phosphorylation of MDM2 at Ser395. To understand the mechanism by which PNUTS destabilizes MDM2, we first analyzed the effect of PNUTS on interaction between p53 and MDM2. Co-immunoprecipitation revealed that PNUTS overexpression had no significant effect on p53MDM2 interaction (Figure 8a). In addition, PNUTS was not 
a

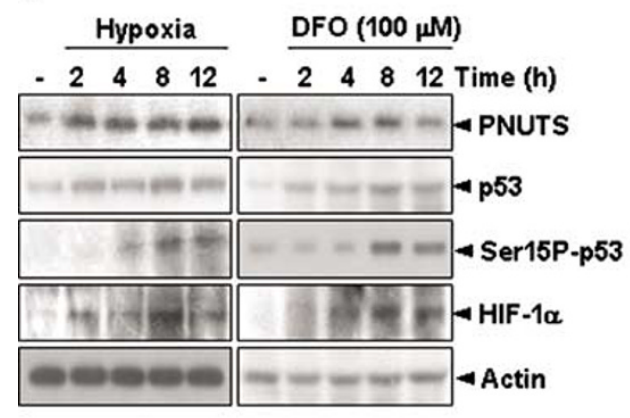

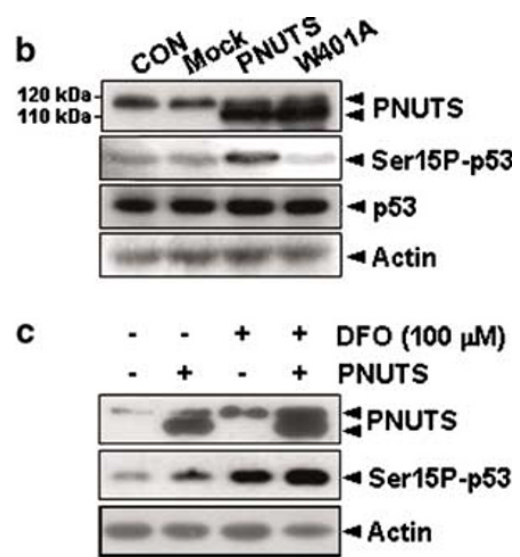

d

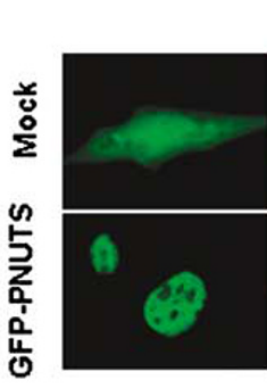

p53

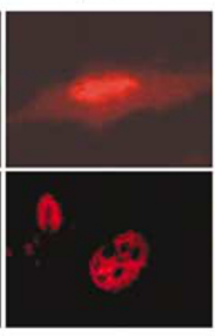

Ser15P-p53

e

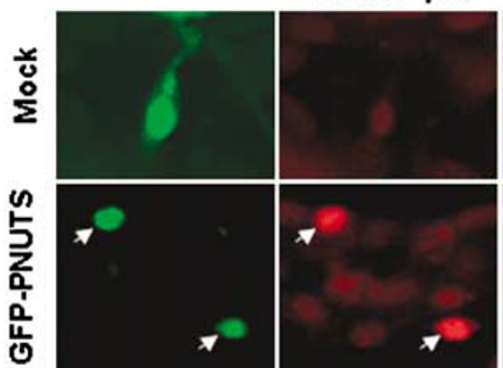

DAPI

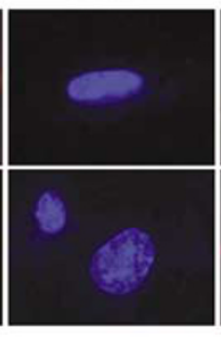

DAPI

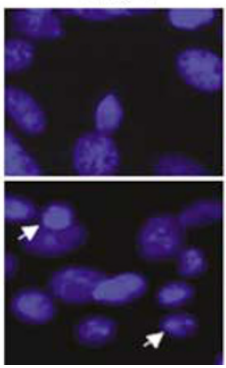

Merge

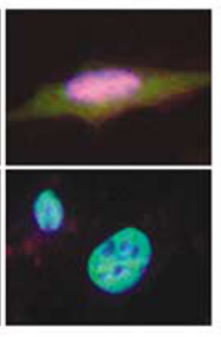

Merge

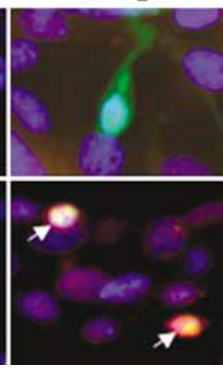

Figure 5 PNUTS regulates phosphorylation and localization of p53. (a) HEK 293 cells were treated with hypoxia (left panel) or $100 \mu \mathrm{M} \mathrm{DFO}$ (right panel) for 0, 2, 4, 8, and $12 \mathrm{~h}$ Cells were then lysed and separated on an SDS-PAGE gel. Western blot was performed using respective antibodies. (b) HEK 293 cells were transfected with pcDNA3.1 plasmid containing PNUTS or pcDNA3.1 plasmid containing the W401A mutant for $48 \mathrm{~h}$ and levels of endogenous p53 and phospho-p53 (Ser 15) protein levels were determined by Western blot. (c) HEK 293 cells were transfected with pcDNA3.1 or pcDNA3.1 with rat PNUTS (wild type) and cells were cultured in the presence or absence of $100 \mu \mathrm{M}$ DFO for $8 \mathrm{~h}$. Cells were then lysed and analyzed by Western blot. (d, e) EC219 cells were grown on coverslips for $24 \mathrm{~h}$ and then transfected with pEGFP or $\mathrm{pEGFP}$ PNUTS (white arrows). Endogenous p53 (d) or phospho-p53 (Ser 15) (e) proteins were detected by immunofluorescence

directly associated with MDM2 (Figure 8a). As the stability of MDM2 is regulated by phosphorylation of serine $395,{ }^{21}$ we attempted to examine whether PNUTS affects MDM2 phosphorylation. Maya et al. ${ }^{21}$ have demonstrated that the 2A10 monoclonal antibody, which has putative epitopes at positions corresponding to residues 258-260 and 393-395, has a reduced reactivity with phophorylation or mutation of MDM2 at serine 395. MDM2 underwent rapid ATMdependent phosphorylation of serine 395 in response to ionizing radiation and this resulted in a decrease in its reactivity with the $2 \mathrm{~A} 10$ monoclonal antibody. ${ }^{21}$ Importantly, cotransfection of wild-type MDM2 with PNUTS but not the W401A mutant resulted in a significant decrease in 2A10 reactivity (Figure $8 \mathrm{~b}$ and $\mathrm{c}$ ). This was not due to differences in the total amount of exogenous MDM2, as confirmed by reprobing the same membrane with anti-Flag antibody (Figure $8 b$ and $c$ ). In contrast to wild-type MDM2, the 2A10 reactivity of the S395A mutant was unaffected by PNUTS (Figure 8b), supporting that $\mathrm{S} 395$ is specifically modified by PNUTS. As PNUTS could increase MDM2 phosphorylation by blocking the access of PP1 to MDM2-associated complexes, we next examined the involvement of PP1. We have previously demonstrated that PNUTS can form complex with PP $1 \alpha$ in the nucleus. ${ }^{5}$ Interestingly, $\mathrm{PP} 1 \alpha$ was apparently present in the MDM2 immunoprecipitates in mock-transfected cells (Figure $8 \mathrm{c}$ ). The amount of PP1 bound to MDM2-associated complexes was markedly reduced by PNUTS overexpression but not by the W401A mutant (Figure 8c). Furthermore, endogenous MDM2 was co-precipitated with PP1 $\alpha$ and the level of MDM2 precipitated 

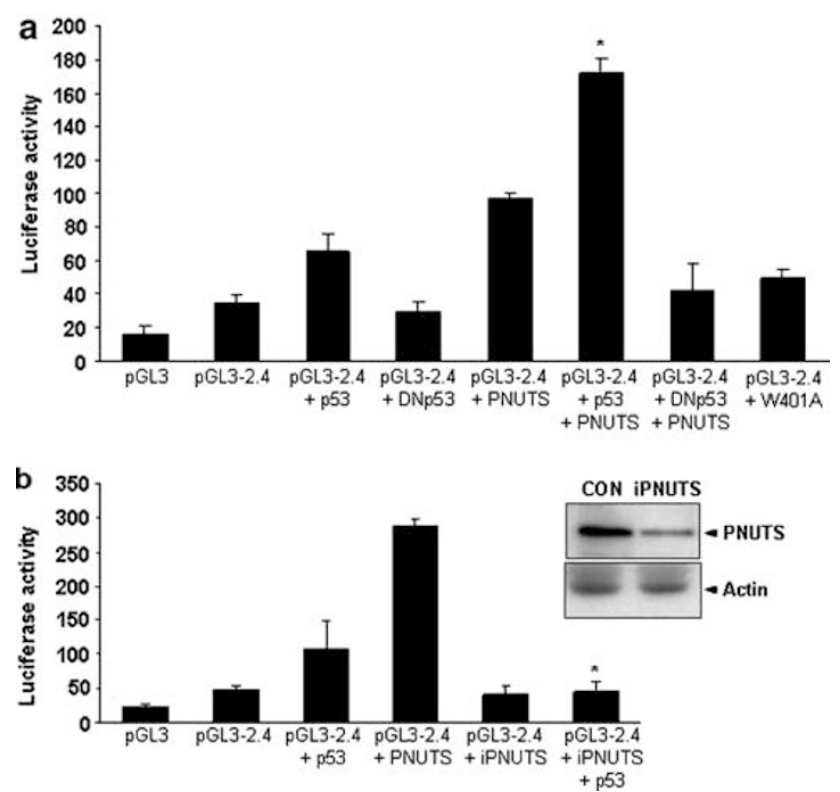

Figure 6 PNUTS increases the transactivation function of p53. (a) HEK 293 cells were cotransfected with expression vectors for PNUTS, the W401A mutant, p53, and/or dominant-negative p53 (DNp53) together with the response promoter for p53 (pGL3-2.4). ${ }^{*} P=0.0001$ versus pGL3 $2.4+p 53(n=3)$. (b) Cells were cotransfected with siRNA constructs for PNUTS (iPNUTS), expression vectors for PNUTS, and/or p53 together with pGL3-2.4. ${ }^{*} P=0.01$ versus $\mathrm{pGL} 32.4+\mathrm{p} 53$ $(n=3)$

with PP1 $\alpha$ was significantly abrogated by wild-type PNUTS overexpression but not by the W401A mutant (Figure 8d).

\section{Discussion}

The present study demonstrates that PNUTS is a novel hypoxia-inducible gene that sensitizes cells to undergo apoptosis under hypoxic conditions. Both mRNA and protein expression of PNUTS were detected in various cell lines, and their expression levels were significantly increased by hypoxia. Using sequence analysis of the PNUTS promoter region, three potential HREs were identified, and one functional HRE site was substantiated by deletion analysis and by response to HIF- $1 \alpha$. Thus, PNUTS may be added to the list of HIF- $1 \alpha$ target genes.

As the expression pattern of PNUTS in response to hypoxia was quite reminiscent of that of $p 53$, which is a major player in hypoxia-induced cell death, ${ }^{10}$ the effects of PNUTS on cell growth and death were analyzed. FACS analysis showed that overexpression of PNUTS in mammalian cells increased the population of cells in the G1 phase (data not shown). This was consistent with accumulation of cyclin D1. Either overexpression of PNUTS or hypoxia up to $48 \mathrm{~h}$ slightly increased apoptotic cell death in cultured cells. However, a combination of these factors resulted in a significant increase in apoptosis upon $24 \mathrm{~h}$ of hypoxia, with a major decrease in cells in G1. Similar results were observed in cells treated with the hypoxia mimetic chemical DFO.

It is known that p53 regulates several $\mathrm{BH} 3$ domain-only proteins that promote apoptosis. ${ }^{22-24}$ Among these proteins, Bax was the first identified p53-regulated pro-apoptotic $\mathrm{Bcl}-2$ family member. ${ }^{22,23}$ Consistently, our data showed that the protein level of Bax was significantly elevated in PNUTSoverexpressing cells under hypoxia compared to mockinfected cells. These results indicate that a high level of PNUTS expression is capable of increasing susceptibility of cells to commit to death in response to hypoxia, potentially through regulation of p53-dependent pro-apoptotic gene expression.

The present study reveals the involvement of PNUTS in the regulation of phosphorylation and transcriptional activity of p53. Previous studies have shown that there are at least eight phosphorylation sites within the $\mathrm{N}$-terminal subdomain, serines $6,9,15,20,33,37$, and 46 and threonine 18, but the functions of several of these phosphorylation sites are not clear. ${ }^{25}$ Among the serines, the phosphorylation of serine 15 is suggested to play a crucial role in the transactivation process by increasing the binding of $p 53$ to $C B P / p 300 .^{26}$ Recently, it has also been reported that PP1, but not PP2A, dephosphorylates phospho-p53 (Ser15). ${ }^{20,26}$ Our data showed that overexpression of PNUTS greatly increased Nterminal phosphorylation of p53 at serine 15 (Figure $5 \mathrm{~b}$ ) as well as at other sites such as serines 6 and 9 (data not shown). However, the mutant PNUTS, W401A, which is devoid of binding ability to PP1, failed to increase p53 phosphorylation. Consistent with the role of N-terminal phosphorylation of p53 in its transcriptional activity, wild-type PNUTS, but not the W401A mutant, significantly enhanced the transcriptional activity of p53. These results indicate that the association of PNUTS with PP1 is required for exerting its regulatory activity with regard to $\mathrm{p} 53$ phosphorylation and transcriptional activity. However, the question to be addressed is whether PNUTS acts as a direct nuclear inhibitor of PP1 towards phospho-p53 under physiological conditions. Previous reports have suggested the possibility that PNUTS may act as both an inhibitor and a targeting subunit of PP1. A recombinant PNUTS (309$691 \mathrm{aa})$ fragment potently inhibited the catalytic activity of PP1 towards an exogenous substrate in vitro. ${ }^{5}$ However, the PNUTS:PP1 holoenzyme is closely involved in chromosome decondensation in vitro, and PNUTS appears to function as a PP1-targeting subunit in this process, $^{7}$ suggesting that PNUTS does not act as a direct inhibitor of the catalytic subunit of PP1. Alternatively, it seems possible that PNUTS may disturb PP1 binding with p53, thus interfering with the dephosphorylation of p53 and consequently resulting in increasing the amount of phospho-p53.

Our data also show that overexpression of PNUTS induces MDM2 degradation. MDM2 possesses the activity of an E3 ubiquitin ligase which mediates auto-ubiquitination as well as the ubiquitination of other substrates including $p 53 .{ }^{27-30}$ The balance between auto- and substrate ubiquitination of MDM2 is modulated physiologically by post-translational modifications, including sumoylation and phosphorylation. ${ }^{31}$ The MDM2 protein is phosphorylated at multiple sites in vivo and these phosphorylations are shown to affect the ligation of MDM2 with p53, ubiquitination, and stability, and association with other proteins such as p300 and ARF. ${ }^{31}$ In this study, we showed that wild-type PNUTS, but not the W401A mutant, induced MDM2 ubiquitination and subsequent degradation, suggesting a role for PP1 in PNUTS-mediated MDM2 auto-ubiquitination. Two possibilities are suggested for the 
a

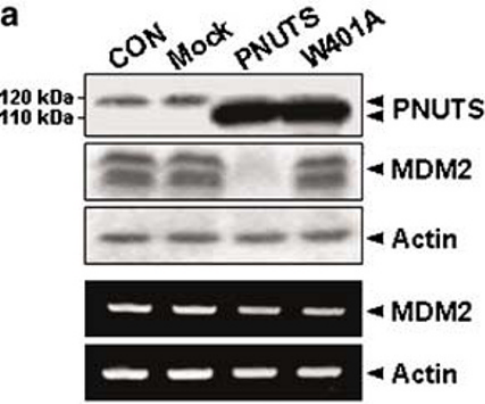

c

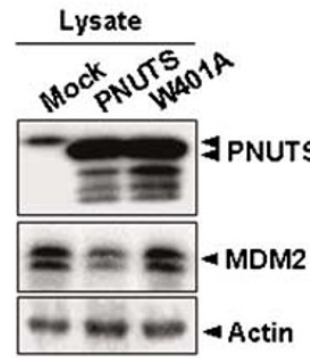

b

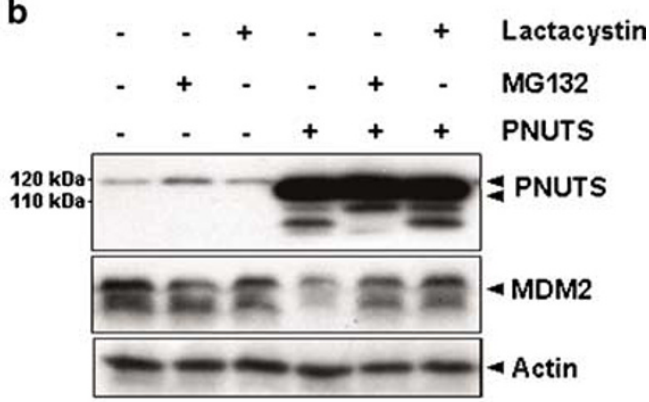

d

MDM2
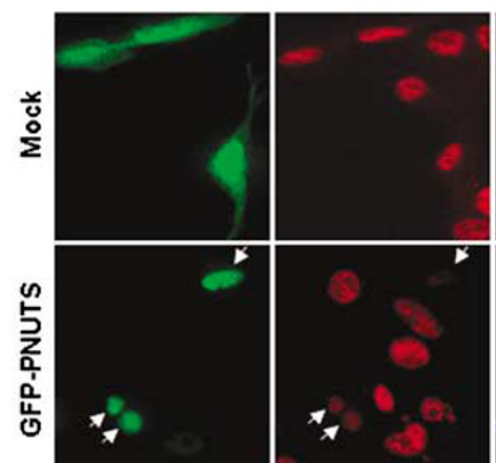

DAPI

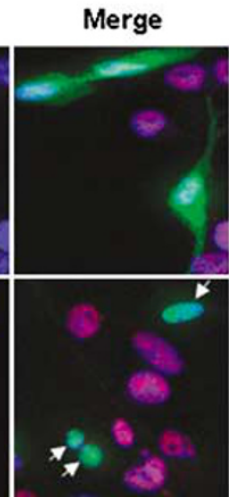

Figure 7 PNUTS regulates the protein stability of MDM2. (a) HEK 293 cells were transfected with the pcDNA3.1 plasmid containing wild-type PNUTS or pcDNA3.1 containing the W401A mutant for $48 \mathrm{~h}$, and protein (upper panel) and mRNA levels (under panel) of MDM2 were determined. (b) HEK 293 cells were transiently transfected with the pcDNA3.1 plasmid or pcDNA3.1 containing PNUTS for $40 \mathrm{~h}$ and then treated with MG132 $(20 \mu \mathrm{M})$ or lactacystin $(10 \mu \mathrm{M})$ for $8 \mathrm{~h}$. (c) HEK $293 \mathrm{cells}$ were transfected with Flag-tagged MDM2 and pCl-Ub expression plasmids together with a control or PNUTS or W401A expression plasmids. Transfected cells were treated with $50 \mu \mathrm{M}$ MG132 for $4 \mathrm{~h}$ and cell lysates were immunoprecipitated. Cell extracts were analyzed by immunoblotting using anti-Flag, anti-MDM2, anti-PNUTS, or anti- $\beta$-actin antibodies. (d) EC219 cells were grown on coverslips for $24 \mathrm{~h}$ and then transfected with pEGFP or pEGFP-PNUTS. Endogenous MDM2 proteins were detected by immunofluorescence

mechanism by which PNUTS induces MDM2 ubiquitination and degradation. It can directly or indirectly regulate the phosphorylation states of MDM2. In the other case, PNUTS may induce the dissociation of MDM2 from p53 and promote MDM2 auto-ubiquitination. A previous study suggested that phosphorylation of serine 15 of p53 may be involved in the inhibition of p53 binding by MDM2. ${ }^{32}$ However, other study showed that phosphorylation at serine 15 does not have a major effect on MDM2-p53 interaction. ${ }^{33}$ Therefore, the role of serine 15 phosphorylation of p53 in MDM2 degradation is controversial. Our data revealed that PNUTS did not bind to MDM2 and also had no significant effect on p53-MDM2 interaction. Thus, it is unlikely that PNUTS induces degradation of MDM2 by dissociating MDM2 from p53. Alternatively, we found that PNUTS overexpression significantly enhanced phosphorylation of MDM2 at serine 395, which is a known phosphorylation site for promoting MDM2 degradation (Figure 8). This increased phosphorylation may be due to either activation of protein kinases such as $\mathrm{ATM}^{33}$ or inhibition of responsible protein phosphatases. Interestingly, our data showed that PP1 is apparently present in the MDM2 immunoprecipitates and the amount of PP1 precipitated with MDM2 was significantly abrogated by PNUTS. This inverse correlation between phosphorylation of MDM2 and its association with PP1 suggest that PNUTS may increase the phosphorylation state of MDM2 by hampering PP1 targeting to MDM2. This notion is further supported by the data that the W401A mutant failed to increase MDM2 phosphorylation and block the binding of PP1 to MDM2-associated complexes. Taken together, we propose the possibility that PNUTS could 

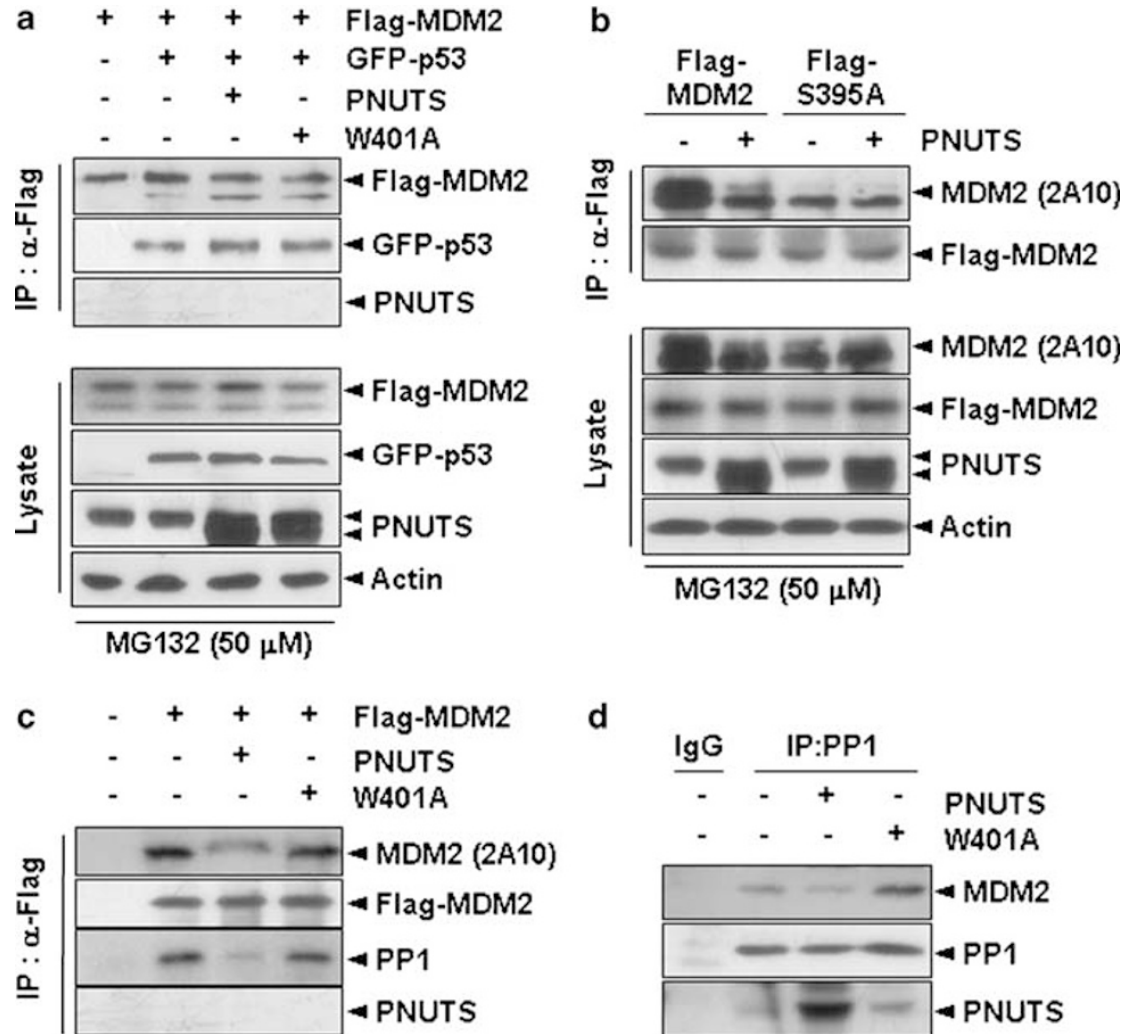

d
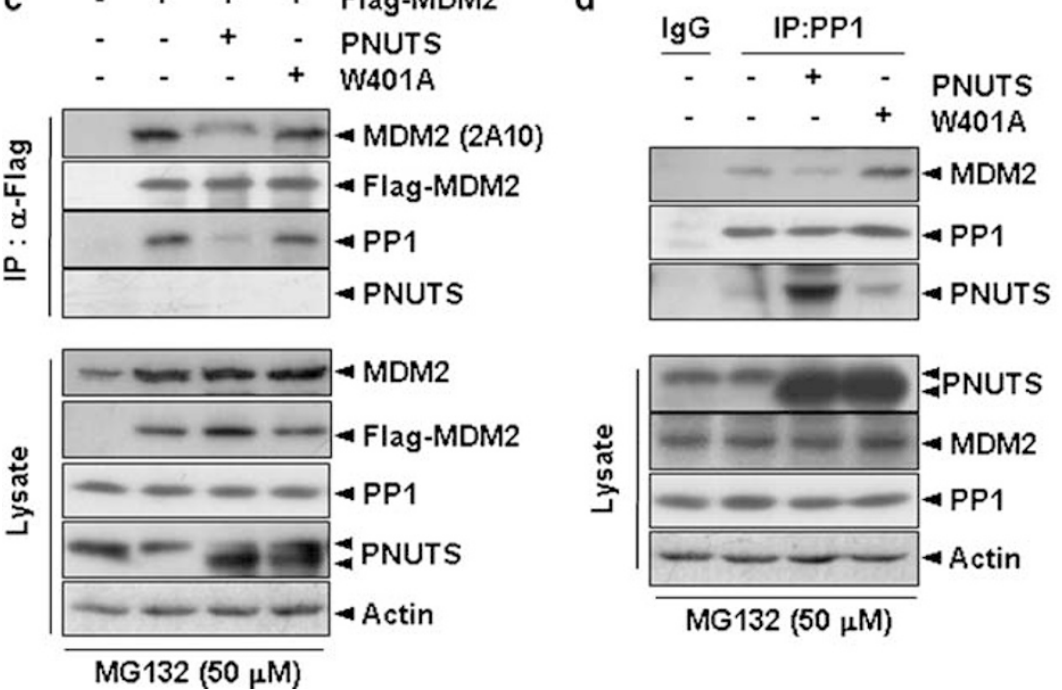

Figure 8 PNUTS increases phosphorylation of MDM2 at serine 395 and dissociates PP1 from MDM2-asscociated complexes. (a) HEK 293 cells were transfected with Flag-tagged MDM2 and pEGFP-C3-p53 expression plasmids together with a control or PNUTS or W401A expression plasmids. Transfected cells were treated with $50 \mu \mathrm{M}$ MG132 for $4 \mathrm{~h}$ before harvesting cells, and then Flag-MDM2 was immunoprecipitated from cell lysates with anti-Flag antibody. (b) Cells were transiently transfected with either wild-type or S395A MDM2 expression plasmids, plus either empty vector or PNUTS expression plasmid. Transfected cells were treated with $50 \mu \mathrm{M}$ MG132 for $4 \mathrm{~h}$ and lysates were immunoprecipitated with anti-Flag antibody. The membrane was first reacted with anti-MDM2 antibody (2A10), followed by reprobing with an anti-Flag antibody. (c) Cells were transfected with Flag-tagged MDM2 expression plasmid together with a control or PNUTS or W401A expression plasmids. Transfected cells were treated with $50 \mu \mathrm{M}$ MG132 for $4 \mathrm{~h}$ and cell lysates were immunoprecipitated with anti-Flag antibody. (d) Cells were transfected with pCDNA 3.1-PNUTS or pcDNA 3.1-W401A plasmids. Endogenous PP1 was immunoprecipitated with anti-PP1 $\alpha$ antibody. Western blot was performed with respective antibodies

regulate the stability of MDM2 protein at least in part by blocking PP1-mediated dephosphorylation of MDM2 at serine 395.

Our fluorescence experiments further showed that overexpression of PNUTS resulted in a significant increase in the serine 15 phosphorylation of $p 53$ and conversely a decrease in the protein level of MDM2 in the nucleus (Figures 5 and 7). MDM2 has also been shown to block the interaction of p53 with the transcriptional apparatus ${ }^{34}$ and mediate translocation of p53 to the cytoplasm, ${ }^{35}$ thereby removing it from its site of action. Consistent with the decrease in MDM2 in cells overexpressing PNUTS, nuclear translocation of cytosolic p53 was observed (Figure 5). These findings together suggest that the PNUTS-PP1 system may act as a novel regulator of $\mathrm{p} 53$ by controlling the phosphorylation state and localization of p53 and stability of its regulatory protein MDM2. The detailed regulatory mechanisms of this system await further investigation.

In conclusion, although this study does not prove the physiological role of endogenous PNUTS in hypoxia-induced cell death, it is evident that PNUTS is a hypoxia-responsive gene that enhances p53-dependent transcription. As MDM2 overexpression, amplification, or activation is significantly involved in the development of many tumors, ${ }^{36}$ it is conceivable that the ability of PNUTS to enhance the sensitivity of cells to hypoxia-induced cell death and inactivate 
Table 1 Nucleotide sequences of primers employed for the generation of deletion mutants by overlap extension PCR

\begin{tabular}{lll}
\hline PNUTS promoter mutant & FMP sequence $\left(\mathbf{5}^{\prime}-\mathbf{3}^{\prime}\right)$ & RMP sequence $\left(\mathbf{5}^{\prime}-\mathbf{3}^{\prime}\right)$ \\
\hline-1216 to $+22(\Delta-795$ to -791$)$ & ctaagacac/gaaggtctccac & gagaccttc/gtgtcttagctg \\
-1216 to $+22(\Delta-775$ to -771$)$ & $\frac{\text { ggtctccac/attcctgacagt }}{\text { ctaagacac/attcctgacagt }}$ & $\underline{\text { gtcaggaat/gtggagaccttc }}$ \\
-1216 to $+22(\Delta-795$ to -771$)$ & $\underline{\text { ctaat/gtgtcttagctg }}$ \\
\hline
\end{tabular}

The linker sequences in each primer are underlined; the linker was designed to span each deletion but contains a 9-nt sequence at both sides of the deletion. Thus each primer contains an 12-nt linker that is complementary to the template

MDM2 function would provide a potentially significant therapeutic approach for targeting tumors. Combining p53 and PNUTS may provide more selectivity for hypoxic tumor cells and reduce the adverse effects on cells in the normal environment. $^{37-39}$

\section{Materials and Methods}

Cell lines and cell culture. Human embryonic kidney cells (HEK 293) and rat brain endothelial cells (EC219) were maintained in Dulbecco's modified Eagle's medium (DMEM) supplemented with 10\% fetal bovine serum, $100 \mathrm{U} / \mathrm{ml}$ penicillin, and $100 \mu \mathrm{g} / \mathrm{ml}$ streptomycin (Gibco-BRL). Cells were incubated at $37^{\circ} \mathrm{C}$ with $5 \%$ $\mathrm{CO}_{2}$ in a humidified chamber.

Plasmid construction. DNA fragments of wild-type PNUTS were amplified by Pfu polymerase. PCR products were digested by EcoRI and Notl and subcloned into pcDNA 3.1. The human PNUTS promoter (1238 bp), spanning -1216 to $+22 \mathrm{bp}$, was amplified by PCR with primers containing $5^{\prime}$ Kpnl and $3^{\prime}$ Hindll sites. The resultant PCR fragment was digested with Kpnl and Hindlll and cloned into the pGL3-basic vector (Promega). Synthetic oligonucleotide sense and antisense primers were used to generate a series of DNA fragments with successive $5^{\prime}$ deletions. All PCR products were digested with Kpnl and Hindll and cloned into the pGL3-basic vector. The following deletion constructs of the human PNUTS promoter were generated: -978 to $+22,-728$ to +22 , and -478 to +22 . The murine stem cell virus (pMSCV puro, Clontech) was used for the construction of the PNUTS full-length $(2.7 \mathrm{~kb})$ expression plasmid. PNUTS DNA was amplified by PCR. The synthesized DNA was digested with EcoRI and Xhol enzymes, purified, and cloned into the pMSCV puro vector.

Reverse transcriptase-polymerase chain reaction analysis. Total RNA from EC219 and HEK 293 cells was acquired using TRIzol reagent (Invitrogen) and various amounts of total RNA $(0.5-5 \mu \mathrm{g})$ were utilized in reverse transcriptasepolymerase chain reaction (RT-PCR) assays. cDNA was amplified for 25 cycles with gene-specific primers: sense, $5^{\prime}$-CAG ACC CGT TCA CCA GAA AT- $3^{\prime}$ and antisense, $5^{\prime}$-GCT GCT ACC ACA GTG ATG ATG ACA A-3' for PNUTS; and sense, $5^{\prime}$-GAA GTG GTG AAG TTC ATG GAT GT- $3^{\prime}$ and antisense, $5^{\prime}$-CGA TCG TTC TGT ATC AGT CTT TCC- $3^{\prime}$ for VEGF. Correlations between the amounts of RNA used and of PCR products obtained for both targets (PNUTS and VEGF) were calculated, and $\beta$-actin served as an internal standard.

Immunoprecipitation. Cells were transfected using Lipofectamine (Invitrogen) and were lysed after $24 \mathrm{~h}$ in lysis buffer. Cell lysates were adjusted to $0.1 \% \mathrm{NP}-40$ and incubated for $4 \mathrm{~h}$ at $4{ }^{\circ} \mathrm{C}$ with anti-FLAG resin (Sigma). The immune complexes were retrieved by low-speed centrifugation, and the resin was washed extensively with binding buffer containing $0.1 \% \mathrm{NP}-40$ and eluted with buffer containing $20 \mathrm{mM}$ Tris- $\mathrm{HCl}$ and $2 \%$ SDS.

Western blot analysis. Cell lysates from HEK 293 and EC219 cells were electrophoresed on an SDS-PAGE gel and transferred to a polyvinyldifluoride membrane. The membranes were blocked and then incubated with the designated antibodies (PNUTS I-25 monoclonal antibody was a kind gift from BodyTech, p53 and phospho-p53 (Ser15) antibodies, hypoxia-inducible factor $1 \alpha$ (HIF-1 $\alpha$ ), MDM2, and actin antibodies were purchased from SantaCruz) and the immunoreactive bands were visualized using a chemiluminescent reagent as recommended by the manufacturer (Amersham Pharmacia Biotechnology).
PCR-mediated deletion mutagenesis. For the creation of each hypoxia response element (HRE) deletion mutation, a mutagenic primer (forward mutagenic primer (FMP)) was designed to contain an $18 \mathrm{bp}$ linker spanning each desired deleted region, with $9 \mathrm{bp}$ to each side of the deletion (Table 1). A second mutagenic primer (reverse mutagenic primer (RMP)) was designed to encode an $18 \mathrm{bp}$ linker complementary to the FMP (Table 1). Two PCRs were performed to produce overlapping products: the first was performed with an upstream primer and an RMP, and the second was performed with a downstream primer and an FMP, with the wild type used as a template. A mixture of two purified PCR products, which overlapped by $10 \mathrm{bp}$, served as the template for a third PCR, which was performed with the upstream ( $5^{\prime}$-CGG GGT ACC GAG AAA CTG TCC TCA GGT CGT-3') and the downstream (5'-CCC AAG CTT TAA ACG AAC CCC AGA ATG GC-3') primers. This final PCR product was gel purified, digested with Hindll and Kpnl, and then inserted into pGL3-basic vector. The primers used are described in Table 1.

Luciferase assay. HEK 293 cells were cotransfected at approximately 60 $80 \%$ confluency with the PNUTS promoter luciferase fusion DNA reporter construct and the $\beta$-galactosidase control vector by Lipofectamine reagent (Invitrogen). Cells were then cultured in DMEM supplemented with $10 \%$ fetal bovine serum for $24 \mathrm{~h}$, treated for $8 \mathrm{~h}$ under hypoxia, and harvested. Cell lysate luciferase activity was measured using the Luciferase Reporter Assay System (Promega). Luciferase activities were normalized with respect to parallel $\beta$-galactosidase activities, to correct for differences in transfection efficiency. Results for each reporter construct were expressed as fold induction compared with cells transfected with pGL3-Basic. Means were calculated from at least four independent experiments.

Generation of stable transfectants using retroviral vectors. The pMSCV puro vector or pMSCV puro vector containing rat PNUTS full-length was introduced into HEK 293T cells (packaging cell line) with $1 \mu \mathrm{g}$ of pVSV-G vector (Clontech) using Lipofectamine according to the manufacturer's instructions. The next day, the viral supernatant from these cells was added with $5 \mu \mathrm{g} / \mathrm{ml}$ of polybrene to EC219 cells. After $24 \mathrm{~h}$ incubation, the medium was replaced with fresh medium containing $3 \mu \mathrm{g} / \mathrm{ml}$ of puromycin. Selection of clones was carried out for 1 week in the presence of $3 \mu \mathrm{g} / \mathrm{ml}$ of puromycin. PNUTS protein expression was confirmed by Western blot.

RNA interference. Ambion web-based criteria were used to determine the small inhibitory RNA (siRNA) target sequence for PNUTS. PNUTS-specific siRNA was generated using the Silencer ${ }^{\mathrm{R}}$ siRNA Construction Kit (Ambion). DNA oligonucleotide (29-mer) templates composed of 21 nucleotides encoding the siRNA and eight nucleotides complementary to the T7 promoter primer were synthesized. The templates used to generate control siRNA were as follows: sense, 5'-AAT TAA AGG TCC CAT CCA CAC CCT GTC TC-3'; and antisense, 5'-AAG TGT GGA TGG GAC CTT TAA AAT GTC TC-3'. The templates used to generate PNUTS siRNA were: sense, $5^{\prime}$-AAT TGG AAA TCC CAT CCA CAC CCT GTC TC$3^{\prime}$; and antisense, $5^{\prime}$-AAG TGT GGA TGG GAT TTC CAA CCT GTC TC-3'. Each siRNA template was hybridized to a T7 promoter primer and then extended by the Klenow DNA polymerase. The extended sense and antisense siRNA templates were transcribed by T7 RNA polymerase, and corresponding transcripts were hybridized to create double-stranded siRNA according to the manufacturer's guidelines.

Trypan blue and annexin $\mathbf{V}$ staining. Trypan blue $(0.5 \mathrm{ml}, 0.4 \%)$ and PBS $(0.3 \mathrm{ml})$ (Biochrom) were added to $0.1 \mathrm{ml}$ of the cell suspension. After incubation, stained cells were counted using a hemocytometer. Annexin $\mathrm{V}$ was used to better investigate the stage of apoptosis by flow cytometry. Cells $\left(1 \times 10^{6}\right)$ were washed and resuspended in PBS. Apoptotic cells were identified by double staining with 
recombinant phycoerythrin (PE)-conjugated Annexin V, using an Annexin V-PE Apoptosis Detection kit (BD Biosciences) according to the manufacturer's instructions. Flow cytometric analysis was performed immediately after staining.

Immunocytochemistry. Cells were grown on coverslips, fixed with $2 \%$ paraformaldehyde, washed with PBS, and permeabilized with $0.1 \%$ saponin. After washing with PBS, slides were blocked in $3 \%$ bovine serum albumin, incubated with mouse monoclonal anti-p53, phospho-p53 (Ser15) (BD Transduction Laboratories), or MDM2 (Santa Cruz Biotechnology) antibodies for $2 \mathrm{~h}$ at $4^{\circ} \mathrm{C}$. After rinsing with PBS, slides were incubated with anti-mouse IgG-TRITC (Sigma), counterstained, and observed by laser scanning confocal microscopy (Olympus).

Statistics. Values of different parameters were presented as the mean \pm S.E.M. One-way analysis of variance (ANOVA) was used to compare each parameter. Post hoc Student's t-test was also performed to identify which group difference accounted for the significant overall analysis of variance. A value of $P<0.05$ was considered statistically significant.

Acknowledgements. This project was supported by grant C00054 from the Korea Research Foundation funded of the Korean Government (MOEHRD), Grant M10416130002-04N1613-00210 from Korea Biotech R\&D Group of MoST, and Grant FG06-2-15 of the 21C Frontier Functional Human Genome Project from the MoST.

1. Shenolikar S, Nairn AC. Protein phosphatases: recent progress. Adv Second Messenger Phosphoprotein Res 1991; 23: 1-121.

2. Garcia A, Cayla X, Guergnon J, Dessauge F, Hospital V, Rebollo MP et al. Serine/ threonine protein phosphatases PP1 and PP2A are key players in apoptosis. Biochimie 2003; 8: 721-726.

3. Ceulemans $\mathrm{H}$, Bollen M. Functional diversity of protein phosphatase-1, a cellular economizer and reset button. Physiol Rev 2004; 84: 1-39.

4. Andreassen PR, Lacroix FB, Villa-Moruzzi E, Margolis RL. Differential subcellular localization of protein phosphatase- $1 \alpha, \gamma 1$, and ä isoforms during both interphase and mitosis in mammalian cells. J Cell Biol 1998; 141: 1207-1215.

5. Allen PB, Kwon YG, Nairn AC, Greengard P. Isolation and characterization of PNUTS, a putative protein phosphatase 1 nuclear targeting subunit. J Biol Chem 1998; 273: 40894095.

6. Kim YM, Watanabe T, Allen PB, Kim YM, Lee SJ, Greengard P et al. PNUTS, a protein phosphatase 1 (PP1) nuclear targeting subunit. Characterization of its PP1- and RNAbinding domains and regulation by phosphorylation. J Biol Chem 2003; 278: 13819-13828.

7. Landsverk HB, Kirkhus M, Bollen M, Kuntziger T, Collas P. PNUTS enhances in vitro chromosome decondensation in a PP1-dependent manner. Biochem J 2005; 390: 709717.

8. Semeza GL. Targeting HIF-1 for cancer therapy. Nat Rev Cancer 2003; 3: 712-732.

9. Greijer $A E$, van der Wall $E$. The role of hypoxia inducible factor 1 (HIF-1) in hypoxia induced apoptosis. J Clin Pathol 2004; 57: 1009-1014.

10. Hammond EM, Giaccia AJ. The role of p53 in hypoxia-induced apoptosis. Biochem Biophys Res Commun 2005; 331: 718-725.

11. Xu Y. Regulation of $p 53$ responses by post-translational modifications. Cell Death Differ 2003; 10: 400-403.

12. Kubbutat MH, Ludwig RL, Ashcroft M, Vousden KH. Regulation of Mdm2-directed degradation by the $\mathrm{C}$ terminus of $\mathrm{p} 53$. Mol Cell Biol 1998; 18: 5690-5698.

13. Haupt $Y$, Maya R, Kazaz A, Oren M. Mdm2 promotes the rapid degradation of $p 53$. Nature 1997; 387: 296-299.

14. Kubbutat MH, Jones SN, Vousden KH. Regulation of p53 stability by Mdm2. Nature 1997; 387: 299-303.
15. Fang S, Jensen JP, Ludwig RL, Vousden KH, Weissman AM. Mdm2 is a RING fingerdependent ubiquitin protein ligase for itself and p53. J Biol Chem 2000; 275: 8945-8951.

16. Honda R, Yasuda H. Activity of MDM2, a ubiquitin ligase, toward $p 53$ or itself is dependent on the RING finger domain of the ligase. Oncogene 2000; 19: 1473-1476.

17. Brooks $\mathrm{CL}$, Gu W. Ubiquitination, phosphorylation and acetylation: the molecular basis for p53 regulation. Curr Opin Cell Biol 2003; 15: 164-171.

18. Tibbetts RS, Brumbaugh KM, Williams JM, Sarkaria JN, Cliby WA, Shieh SY et al. A role for ATR in the DNA damage-induced phosphorylation of 553 . Genes Dev 1999; 13: 152-157.

19. Li DW, Liu JP, Schmid PC, Schlosser R, Feng H, Liu Y et al. Protein serine/threonine phosphatase-1 dephosphorylates p53 at Ser-15 and Ser-37 to modulate its transcriptional and apoptotic activities. Oncogene 2006; 28: 3006-3022.

20. Haneda M, Kojima E, Nishikimi A, Hasegawa T, Nakashima I, Isobe K. Protein phosphatase 1 , but not protein phosphatase $2 A$, dephosphorylates DNA-damaging stressinduced phospho-serine 15 of p53. FEBS Lett 2004; 567: 171-174.

21. Maya R, Balass M, Kim ST, Shkedy D, Leal JF, Shifman $O$ et al. ATM-dependent phosphorylation of Mdm2 on serine 395: role in p53 activation by DNA damage. Genes Dev 2001; 15: 1067-1077.

22. Baskin-Bey ES, Gores GJ. Death by association: BH3 domain-only proteins and liver injury. Am J Physiol Gastrointest Liver Physiol 2005; 289: 987-990.

23. Shacka JJ, Roth KA. Regulation of neuronal cell death and neurodegeneration by members of the Bcl-2 family: therapeutic implications. Curr Drug Targets CNS Neurol Disord 2005; 4: 25-39.

24. Zhang XD, Gillespie SK, Borrow JM, Hersey P. The histone deacetylase inhibitor suberic bishydroxamate: a potential sensitizer of melanoma to TNF-related apoptosis-inducing ligand (TRAIL) induced apoptosis. Biochem Pharmacol 2003; 66: 1537-1545.

25. Appella E, Anderson CW. Signaling to p53: breaking the posttranslational modification code. Pathol Biol (Paris) 2000; 48: 227-245.

26. Kar S, Sakaguchi K, Shimohigashi Y, Samaddar S, Banerjee R, Basu G et al. Effect of phosphorylation on the structure and fold of transactivation domain of p53. J Biol Chem 2002; 277: 15579-15585.

27. Fang S, Jensen JP, Ludwig RL, Vousden KH, Weissman AM. Mdm2 is a RING fingerdependent ubiquitin protein ligase for itself and p53. J Biol Chem 2000; 275: 8945-8951.

28. Geyer RK, Yu ZK, Maki CG. The MDM2 RING-finger domain is required to promote p53 nuclear export. Nat Cell Biol 2000; 2: 569-573.

29. Honda $\mathrm{R}$, Tanaka H, Yasuda H. Oncoprotein MDM2 is a ubiquitin ligase E3 for tumour suppressor p53. FEBS Lett 1997; 420: 25-27.

30. Honda R, Yasuda H. Activity of MDM2, a ubiquitin ligase, toward p53 or itself is dependent on the RING finger domain of the ligase. Oncogene 2000; 19: 1473-1476.

31. Meek DW, Knippschild U. Posttranslational modification of MDM2. Mol Cancer Res 2003; 14: $1017-1026$

32. Sakaguchi K. Damage-mediated phosphorylation of human p53 threonine 18 through a cascade mediated by a casein 1-like kinase. Effect on Mdm2 binding. J Biol Chem 2000; 275: 9278-9283.

33. Schon O, Friedler A, Bycroft M, Freund SM, Fersht AR. Molecular mechanism of the interaction between MDM2 and p53. J Mol Biol 2002; 323: 491-501.

34. Momand J, Zambetti GP, Olson DC, George D, Levine AJ. The mdm-2 oncogene product forms a complex with the p53 protein and inhibits p53-mediated transactivation. Cell 1992; 69: $1237-1245$

35. Roth J, Dobbelstein M, Freedman DA, Shenk T, Levine AJ. Nucleo-cytoplasmic shuttling of the hdm2 oncoprotein regulates the levels of the p53 protein via a pathway used by the human immunodeficiency virus rev protein. EMBO J 1998; 17: 554-564.

36. Deb SP. Function and dysfunction of the human oncoprotein MDM2. Front Biosci 2002; 7: 235-243.

37. Haneda M, Kojima E, Nishikimi A, Hasegawa T, Nakashima I, Isobe K. Protein phosphatase 1 , but not protein phosphatase $2 \mathrm{~A}$, dephosphorylates DNA-damaging stressinduced phospho-serine 15 of p53. FEBS Lett 2004; 567: 171-174.

38. Hammond EM, Giaccia AJ. The role of p53 in hypoxia-induced apoptosis. Biochem Biophys Res Commun 2005; 331: 718-725.

39. lida T, Mine S, Fujimoto H, Suzuki K, Minami Y, Tanaka Y. Hypoxia-inducible factor-1alpha induces cell cycle arrest of endothelial cells. Genes Cells 2002; 7: 143-149. 